\author{
Departamento de Indústria, Inspeção e Conservação de Produtos Alimentícios \\ de Origem Animal \\ Diretor: I'rof. P'ssclionl Mucciolo \\ Departamento de Química Orgânica e Biológica \\ Diretor: Prof. Fonseca Kibeiro

\section{DETERMINAÇÃO IODOMÉTRICA DO ÍNDICE DE PERÓXIDOS EM ÓLEO DE CAROÇO DE ALGODÃO, BANHA E MANTEIGA *} \\ (IODOMETRIC, DETERMINATION OF PEROXIDE VALUES IN COTTON \\ SEED OIL, LARD AND BUTTER) \\ P. Mucciolo \\ P. Assis Ribeiro \\ Assistente \\ V. Bonoldi \\ Livre Docente
}

A determinação iodométrica do valor ou índice de peróxidos nos óleos e gorduras comestíveis tem sido preferentemente utilizada nos mais recentes trabalhos referentes à rancificação, como medida do desenvolvimento do processo oxidativo.

1à literatura existente à respeito, pode-se concluir que até o presente não há método químico cujos resultados capacitem o analista a afiançar estar ou não rançosa uma gordura, chegando muitos autores a afirmar que a prova final (e inconteste?) da rancidez é dada pela observação organolética; à êste respeito, não acreditamos ser necessário ressaltar o fraco apôio que deve ser dispensado às provas que se estribem em meros conceitos pessoais, mercê das falhas que êstes podem apresentar.

Dessa maneira, a importância de uma determinação segura por intermédio da qual a rancidez possa ser medida quantitativamente, não precisa ser ressaltada e justifica plenamente a procura a que se dedicam dentro dêsse objetivo, numerosos experimentadores.

Sem dúvida, um dos trabalhos interessantes a êste propósito é 0 de STANSibY referente especialmente ao estudo comparativo entre alguns processos de determinação do índice de peróxidos em óleo de peixc; sôbre o mesmo assunto versa igualmente o presente, tendo os autores trabalhado com manteiga, banha e óleo de caroço de algodão todos de procedência nacional, sujeitando os resultados à análise estatística o que deixou de ser feito por STANSBY. 
Rev. Fac. Med. Vet. S. Paulo - Vol. 3, fasc. 4, 1948

Do trabalho do referido autor - STANSBY - retiramos o quadro abaixo, no qual, após a aplicação de alguns processos iodométricos preconizados para as determinações do índice peróxido, aquêle autor estabelece as

VANTAGENS COMPAIRATIVAS DOS PROCESSOS

\begin{tabular}{|c|c|c|c|}
\hline $\begin{array}{c}\text { Processos } \\
\text { de }\end{array}$ & Vantagens & Desvantagens & Aplicaçño \\
\hline 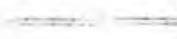 & wroe, $1:=1=0=\cdots=$ & $=-1+n=$ & $==\ldots=$ \\
\hline Whiceler & Fixtrema simplicidade. & $\begin{array}{l}\text { Falta do exutidño. } \\
\text { Resulfudos falhos para } \\
\text { nmostras de pesos di- } \\
\text { ferentes. }\end{array}$ & 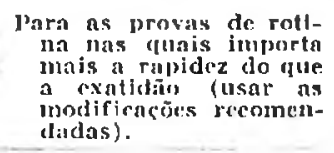 \\
\hline $\begin{array}{l}\text { Acido } \\
\text { cloridrico }\end{array}$ & $\begin{array}{l}\text { Sensibilidnde e precisão } \\
\text { moderadia. }\end{array}$ & $\begin{array}{l}\text { Hesultados apenas regu- } \\
\text { lares no caso de amos- } \\
\text { tris de neso variavel. } \\
\text { laige ntmosfera iner- } \\
\text { te. }\end{array}$ & 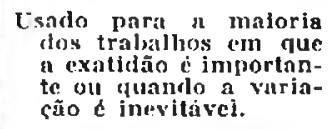 \\
\hline $\begin{array}{l}\text { Actdon } \\
\text { sulfúrico }\end{array}$ & 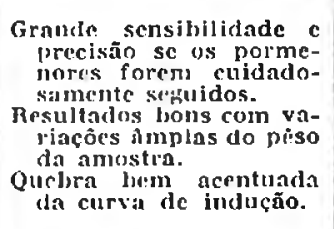 & $\begin{array}{l}\text { Processo algo laborioso } \\
\text { nceessitando prande } \\
\text { atencino nos pormeno- } \\
\text { res, afim de se evitar } \\
\text { erros. }\end{array}$ & $\begin{array}{l}\text { Nãn se recomrnda para } \\
\text { provas ordinárias. }\end{array}$ \\
\hline
\end{tabular}

Do referido trabalho igualmente retiramos o que se refere à téenica da dosagem do valor peróxido, de acôrdo com os diversos processos. Estes, aliás, são abaixo descritos, o que se justifica porque em nosso meio não são suas descrições senão dificilmente acessíveis.

Reagentes:

\section{PROCESSO DF WHEEJER-STANSBY}

1 - Solução de ácido acético e clorofórmio na proporção de $6: 4$.

2 - Soluçāo saturada de iodeto de potássio, de recente preparação.

3 - Solução de ácido cloridrico $\mathrm{N} / 10$.

4 - Solução de tiosulfato de sódio $\mathrm{N} / \mathbf{1 0 0}$.

5 - Solução de amido à $1 \%$.

\section{Técnica:}

a) - pesar 3 a $10 \mathrm{~g}$ da amostra homogenizada $\mathrm{em}$ frasco Frlenmeyer de $250 \mathrm{~cm}^{3}$ de boca esmerilhada; adicionar $10 \mathrm{~cm}^{3}$ da mistura 6:4 de ácido acćtico-clorofórmio; agitar cum movimento de rotação até dissolução; 
b) - adicionar logo depois de efetuada a dissolução acima, 1 $\mathrm{cm}^{3}$ de solução saturada de iodeto de potássio. Humogenizar a distribuição do iodeto com ligeira agitação, deixando então que a mistura reaja no escuro pelo espaço de um minuto;

c) - juntar imediatamente após esgotado o minuto, $50 \mathrm{~cm}^{3} \mathrm{de}$ ácido cloridrico $\mathrm{N} / 10$, sob viva agitação;

(l) - proceder á determinação do iodo libertado, com a solução $0,01 \mathrm{~N}$ de tiosulfato de sódio, usando como indicador, $1 \mathrm{~cm}^{3}$ da solição de amido a $1 \%$; êste deverá ser adicionado tanto quanto possível nas proximidades do ponto final - leve coloração amarelo-palha de iodo ainda em liberdade;

e) - efetuar prova em branco.

\section{JRECATCÕES E ALGLMAS CONSIDERAÇÕES ATINENTES AO PRESENTE PROCESSO}

Além das recomendações que cabem a todos os processos e das quais será feita referência adiante, em parágrafo especial, êste processo, como diz STANSBY, apresenta grande percentagem de variabilidade quando aplicado sôbre pesos diversos da amostra; segundo nossas observações, mesmo sôbre pesos muito próximos da mesma amostra, a percentagem de variabilidade é grande. A homogenização, a mistura com os diversos reagentes, o tempo de permanência de contato do iodeto de potássio e a adição da solução de amido, tudo deve ser cuidadosamente respcitado tal como explicitamente estatuíco.

\section{Reagentes:}

\section{PROCESSO DO ACIDO CLORIDRICO}

1 - Clorofórmio ou tetracloreto de carbôno.

2 - Anidridio carbônico produzido em aparelho de Kipp ou de torpedo.

3 - Ácido acético glacial puríssimo, contendo 4 por mil de ácido cloridrico concentrado.

4 - Solução saturada de iodeto de potássio, de recente preparação.

5 - Solução de tiosulfato de sódio $\mathrm{N} / 100$.

6 - Solução de amido a $1 \%$.

Técnica:

a) - pesale de 3 a 10 g da amostra fundida e filtrada em frasco Erlenmeyer de 250-500 $\mathrm{cm}^{3}$, preferivelmente de boca esmerilhada;

b) - dissolver em $20 \mathrm{~cm}^{3}$ de clorofórmio ou tetracloreto de carbôno, humogenizando com ligeiro movimento de rotação; no caso de gordura, fundir em banho-maria; 

bônico ;

c) - na solução, passar corrente vigorosa de anidrido car-

d) - adicionar $30 \mathrm{~cm}^{3}$ de ácido acético contendo $4 \mathrm{~cm}^{3}$ de ácido clorídrico concentrado por litro e continuar a borbulhar o anidrido carbônico pelo espaço de um minuto, findo o qual diminuir para cêrca de uma bôlha por segundo;

e) - juntar $1 \mathrm{~cm}^{3}$ da solução saturada de iodeto de potássio e após decorridos 5 minutos, adicionar $100 \mathrm{~cm}^{3}$ de água distilada (250 $\mathrm{cm}^{3}$ caso o óleo seja escuro);

f) - dosar o iodo livre por solução de tiosulfato de sódio $\mathrm{N} / 100$ usando como indicador a solução de amido a $1 \%$ devendo êste ser adicionado tanto quanto possível próximo ao ponto final - leve coloração amarelo-palha de iodo ainda em liberdade;

g) - prova em branco.

\section{PRECAUÇOEES E ALGUMAS CONSIDERAÇOES ATINENTES AO PRESENTE PROCESSO}

No que se refere à homogenização e mistura com os diversos graus de agitação, os tempos de permanência sob corrente de anidrido carbônico, contato com o iodeto de potássio e a adição da solução de amido, as recomendações devem ser rigorosamente observadas para que os resultados se enquadrem dentro do que objetiva o processo, ou seja, exatidão dentro de amostras de pesos muito próximos.

Além disto o contato com o ar, além da exposição à luz, acelera a reação pelo que, iniciada a determinação, deve esta prosseguir sem interrupções até a fase final da valorização do iodo. Mais: o alongamento do periodo de contato dos reagentes, antes da adição do iodeto de potássio, dá lugar a valores mais baixos de peróxido, recomendando-se por isso que as operaçōes que precedem a referida adição, realizem-se tanto quanto possivel dentro de espaços de tempo iguais. Outra causa de baixos valores peróxido é o uso de ácido acético de concentração inferior à recomendada.

\section{Reagentes:}

\section{PROCESSO DO ACIDO SULFGRICO}

1 - Solução aquosa saturada e de recente preparação, de iodeto de potássio.

2 - Água distilada. torpedo.

3 - Anidrido carbônico, produzido em aparelho de Kipp ou de

4 - Tiosulfato de sódio $N / 200$.

5 - Solução aquosa a $1 \%$ de amido. 
6 - Soluto solvente recentemente preparado:

Acido acético glacial . . . . $30 \mathrm{~cm}^{3}$

Clorofórmio . . . . . . $20 \mathrm{~cm}^{3}$

Ácido sulfúrico concentrado . $\quad 0.5 \mathrm{~cm}^{3}$

7 - Clorofórmio.

Técnica:

Inicialmente, o solvente e reagentes (exceto o tiosulfato de sódio) devem ser resfriados a cêrca de $l^{\circ} \mathrm{C}$ (banho de gêlo em fusão) e saturados com corrente de anidrido carbônico, ou nitrogênio.

a) - pesar aproximadamente $5 \mathrm{~g}$ da amostra num bequer de $50 \mathrm{~cm}^{3}$ de capacidade; dissolver com clorofórmio, completando o volume a $50 \mathrm{~cm}^{3} \mathrm{em}$ matraz aferido; lavar o bequer, o bastão e o funil com clorofórmio, até completar os $50 \mathrm{~cm}^{3}$; agitar bem e filtrar;

b) - a um Erlenmeyer de $500 \mathrm{~cm}^{3}$ no qual estão $50 \mathrm{~cm}^{3}$ do solvente resfriado, juntar $1 \mathrm{~cm}^{3}$ da solução saturada de iodeto de potássio e imediatamente $2 \mathrm{~cm}^{3}$ exatos da dissolução de óleo ou gordura;

c) - o anidrido carbônico ou nitrogênio é levado a passar em corrente lenta através a solução, que permanece mergulhada no banho de gêlo em fusão;

d) - decorridos exatamente 5 minutos, adicionar $250 \mathrm{~cm}^{3}$ de água distilada, resfriada e saturada de graz incrte;

e) - proceder a determinação do iodo libertado com solução de tiosulfato de sódio N/200 juntando o indicador - solução de amido a $1 \%$ - bem próximo ao ponto final, inàicado por uma leve coloração amarelo palha de iodo ainda em liberdade;

f) - efetuar prova em branco.

\section{PRECAUÇÕES F ALGUMAS CONSIDERAÇÕES ATINENTES AO PRESENTE PROCESSO}

Especial atenção deve ser dispensada a todos os pormenores, a fim de que sejam obtidos resultados verdadeiros. STANSBY não observou influência da luz em ausência de ar, mas chama a atenção para a necessidade de se juntar imediatamente após a solução de iodeto de potássio, a amostra do lípido já dissolvido, sem o que são obtidos baixos valores peróxido.

\section{CONSIDERAÇÕES GERAIS E CUIJADOS A PROPOSITO DOS PROCESSOS JDESCRITOS}

No caso de gordura, fundir ràpidamente $\mathrm{em}$ banho maria, antes de adicionar qualquer reagente. 
Quanto a êstes, é de especial importância o uso de ácido acético purìssimo, e antes da realização das determinações, deve o mesmo ser submetido a provas no sentido de averiguar sua capacidade de dar branco excessivamente alto ou negativo, fatos que comprovam ou a capacidade de libertar iodo do iodeto de potássio ou a de combinar-se com o iodo libertado.

O iodeto de potássio deve dar, em soluções saturadas de preparação recente, provas negativas de iodo livre com solução de amido.

Esta solução de iodeto de potássio liberta iodo ràpidamente, especialmente sob a ação da luz. Recomendam alguns autores, STANsBY inclusive, para prevenir esta oxidação, a juntada de carbonato de sódio (à $0,3 \%$ ) com o que a solução se conservaria indefinidamente.

Os solventes e as misturas solventes devem ser, no que diz respeito à capacidade de libertar o iodo da solução saturada de iodeto de potássio, submetidos a provas de período a periodo, especialmente quando fôr usado o processo do ácido sulfúrico.

A solução de tiosulfato de sódio pode ser estabilizada por uma semana - segundo STANSBY - pela adição de carbonato de sódio à $0,01 \%$. O ponto final da reação cuja importância não é necessário encarecer, nos processos propostos tem a solução de amido como indicador. Ora, é sabido que êste absorve o iodo de acôrdo com a concentração dêste no meio. Daí diluir-se a solução e cuidar-se de juntar o indicador quando o iodo livre estiver em mínima quantidade. Casos há em que não se tem indicação certa da oportunidade dessa juntada pois muitos óleos atribuem ao meio coloração semelhante à leve amarelo-palha.

A emulsão que se forma, pois a determinação deve ser feita com agitação constante, é mais uma causa que concorre para perturbar a indicação apropriada do momento de juntar-se o indicatlor. Por esta razão recomendam os autores do presente trabalho a exccução sistemática de provas $\mathrm{cm}$ triplicata $\mathrm{cm}$ determinações por processos como os prescntemente examinados. Acreş̧a-se ainda que no processo do ácido sulfúrico desenvolve-se em alguns óleos, ao invés da coloração azul do complexo amido-iodo, uma coloração púrpura que se atribui à existência da vitamina A no ólco ou gordura. Esste inconveniente perturbador pode ser obviado pela manutenção constante da solução reagente em banho de gêlo funclente.

Finalmente, qualquer que seja o processo cuide-se sempre de juntar imediatamente au lípido dissolvido a solução de iodeto de potássio saturada, bem como usar ácido acético de comprovada pureza 
além de realizar sempre prova em branco para tôdas as determinações feitas.

As amostras deven ser prèviamente muito bem homogenizadas, pois as camadas externas, principalmente na mantciga, geralmente apresentam-se rançosas dias antes desta deterioração manifestar-se nas partes internas.

\section{CáLCULOS}

Para qualquer dos processos aplicados, os resultados exprimem-se em moles de peróxido por $\mathrm{g}$ de lípido, e são calculados de acôrdo com a seguinte fórmula, originariamente proposta por WIIEELER:

$$
\text { moles de peróxidos: } \frac{0,5 \times \mathrm{cm}^{3} \times \mathrm{N}}{\mathrm{g}}
$$

$\mathrm{cm}^{3}=$ centímetros cúbicos de tiosulfalo de sódio gastos.

$\mathbf{N}=$ normalidade do tiosulfato de sódio.

$g$ = gramas do lípido.

Costuma-se também exprimir os resultados por $1.000 \mathrm{~g}$ do lípido, para o que, após aplicar a fórmula acima, multiplica-se o resultado por 1.000 .

\section{PARTE EXPERIMENTAI.}

Para evidenciarmos, dentro do intuito do presente trabalho, qual dos três processos é mais sensivel quando aplicado á banha, á manteiga e ao óleo de caroço de alğodão, determinámos o indice de Peróxidos nessas substâncias; êste indice foi determinado doze vezes pelos três processos no mesmo matcrial. Os pesos utilizados de cada amostra, foram os seguintes, em gramas:

\begin{tabular}{l|c|c|c}
\hline & $\begin{array}{c}\text { Slco de caroco } \\
\text { de algadiio }\end{array}$ & Banha & Manteiga \\
\hline \hline Processo de Wheeler & $4,0482-4,5015$ & $3,4828-3,9454$ & $2,3275-4,0318$ \\
\hline l'rocesso do $\mathrm{HCl}$ & $3,8605-4,9902$ & $3,7440-3,9444$ & $3,3642-3,8000$ \\
\hline Processo do $\mathrm{H}_{2} \mathrm{SO}_{4}$ & 4,2999 & 3,7590 & 3,8363 \\
\hline
\end{tabular}

Os resultados das determinações vão adiante tabelados, seguindo-se o estudo estatístico dos mesmos. 
OLEO DE CAROÇO DE ALGODÃO

Moles de peróxido por $1.000 \mathrm{~g}$ de lípido

\begin{tabular}{c|c|c}
\hline $\begin{array}{c}\text { Processo de } \\
\text { Whecler-Stanshy }\end{array}$ & $\begin{array}{c}\text { Processo do } \\
\text { Acldo cloridrico }\end{array}$ & $\begin{array}{c}\text { Processo do } \\
\text { Acldo sulf urico }\end{array}$ \\
\hline & & \\
2,700 & 2,752 & 29,797 \\
1,559 & 3,328 & 18,895 \\
1,926 & 2,705 & 13,081 \\
1,053 & 4,035 & 21,802 \\
1,990 & 3,367 & 14,535 \\
1,357 & 3,443 & 15,988 \\
1,235 & 3,654 & 24,709 \\
1,166 & 3,459 & 17,442 \\
2,197 & 3,011 & 17,442 \\
0,999 & 2,428 & 10,174 \\
1,269 & 3,712 & 10,174 \\
1,273 & 2,746 & 14,535 \\
\hline
\end{tabular}

BANHA

Moles de peróxido por $1.000 \mathrm{~g}$ de lípido

\begin{tabular}{|c|c|c|}
\hline $\begin{array}{c}\text { Processo de } \\
\text { Wheeler-Stansby }\end{array}$ & $\begin{array}{l}\text { processud do } \\
\text { Acido cloridrico }\end{array}$ & $\begin{array}{l}\text { 'rocesso do } \\
\text { Arido stulfurico }\end{array}$ \\
\hline Cl= & 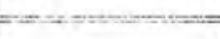 & $1=--+6+0 .=$ \\
\hline 16,664 & 13,702 & 61,519 \\
\hline 13,064 & 14,375 & 48,217 \\
\hline 19,786 & 14,823 & 46,554 \\
\hline 17,383 & 14,576 & 66,507 \\
\hline 18,577 & 14,197 & 56,530 \\
\hline 19,578 & 13,601 & 48,217 \\
\hline 18,956 & 13,492 & 59,856 \\
\hline 14,193 & 15,646 & $58,1,13$ \\
\hline 16,502 & 14,972 & 58,193 \\
\hline 12,209 & 15,055 & 46,554 \\
\hline 17,730 & 15,585 & 54,868 \\
\hline 10,518 & 13,531 & 46,554 \\
\hline
\end{tabular}

MANTEIGA

Moles de peróxido por $1.000 \mathrm{~g}$ de lipido

\begin{tabular}{c|c|c}
\hline $\begin{array}{c}\text { Processo de } \\
\text { Whecler-stanslyy }\end{array}$ & $\begin{array}{c}\text { prowsso do } \\
\text { Acido cloridrico }\end{array}$ & $\begin{array}{c}\text { processo do } \\
\text { Acido sulfurico }\end{array}$ \\
& & \\
1,718 & 2,295 & 17,920 \\
1,967 & 2,236 & 8,145 \\
1,488 & 2,080 & 8,145 \\
1,546 & 2,411 & 8,145 \\
1,668 & 2,326 & 8,145 \\
1,768 & 2,360 & 9,775 \\
1,864 & 2,297 & 14,662 \\
1,465 & 2,282 & 11,404 \\
1,781 & 2,384 & 17,920 \\
1,545 & 2,295 & 14,662 \\
1,399 & 2,372 & 11,404 \\
1,405 & 2,321 & 17,920 \\
\hline
\end{tabular}


COMPARAÇÃo DE PROCESSOS DE DETERMINAÇAO DO VALOR PEROXIDO

\begin{tabular}{|c|c|c|c|c|c|c|c|c|c|}
\hline Material & \multicolumn{3}{|c|}{ óleo de caroço de algodão } & \multicolumn{3}{|c|}{ Banha } & \multicolumn{3}{|c|}{ Manteiga } \\
\hline Processos & Whecler & $\mathrm{HCl}$ & $\mathrm{H}^{2} \mathrm{SO}_{4}$ & Wheeler & $\mathrm{HCl}$ & frssa & Wheeler & $\mathrm{HCl}$ & $\mathrm{H}_{2} \mathrm{SO}_{4}$ \\
\hline $\mathbf{M}$ (média). . . . . & 1,560 & 3,220 & 17,381 & 16,263 & 14,463 & 54,313 & $1,63 \pi$ & 2,305 & 12,354 \\
\hline$\sigma$ (variabilidade). & 0,38 & 0,46 & 5,59 & 2,94 & 0,60 & 6,59 & 0,17 & 0,08 & 3,90 \\
\hline C.V. (\% de variabilidade) & 24,67 & 14,50 & 32,16 & 18,08 & 4,15 & 12,13 & 10,95 & 3,58 & 31,07 \\
\hline $\mathrm{N}$ (N." de mensuraçōes). & 12 & 12 & 12 & 12 & 12 & 12 & 12 & 12 & 12 \\
\hline \multicolumn{10}{|c|}{ ANALISE DE VARIANCIA DOS P } \\
\hline Material & \multicolumn{3}{|c|}{ Oleo de caroşo de algodão } & \multicolumn{3}{|c|}{ Banha } & \multicolumn{3}{|c|}{ Manteiga } \\
\hline Processos & $\begin{array}{l}\text { Wheeler } \\
\text { IICl }\end{array}$ & $\begin{array}{l}\text { Hess } \\
\text { Wheeler }\end{array}$ & ${ }_{\mathrm{HCl}}^{\mathrm{HeSCi}}$ & $\begin{array}{l}\text { Wheeler } \\
\text { Ilcl }\end{array}$ & $\begin{array}{c}\mathrm{H}^{2 S O} \\
\text { Wheeler }\end{array}$ & $\stackrel{\mathrm{HICl}^{2}}{25 \mathrm{O}}$ & $\begin{array}{l}\text { Wheeler } \\
\text { HCl }\end{array}$ & $\begin{array}{c}\text { Meso: } \\
\text { Wheeler }\end{array}$ & $\begin{array}{l}\mathrm{H} 2504 \\
\mathrm{IICl}\end{array}$ \\
\hline F (Teste de variabilidade) & 2,8997 & 1,6978 & 4,9230 & 18,9816 & 2,2151 & 8.5694 & 9,3470 & 8,3288 & 77,8499 \\
\hline No nivel $5 \%$ & $\begin{array}{c}\text { Diferença } \\
\text { signif. }\end{array}$ & $\begin{array}{l}\text { Difcrença } \\
\text { não sig. }\end{array}$ & $\begin{array}{c}\text { Diferença } \\
\text { signif. }\end{array}$ & $\begin{array}{c}\text { Diferença } \\
\text { signif. }\end{array}$ & $\begin{array}{l}\text { Diferença } \\
\text { não sig. }\end{array}$ & $\begin{array}{c}\text { Diferença } \\
\text { signif. }\end{array}$ & $\begin{array}{l}\text { Diferença } \\
\text { signif. }\end{array}$ & $\begin{array}{c}\text { Diferença } \\
\text { signif. }\end{array}$ & $\begin{array}{l}\text { Diferença } \\
\text { signif. }\end{array}$ \\
\hline No nivel $1 \%$ & $\begin{array}{c}\text { Diferença } \\
\text { não sig. }\end{array}$ & , & $\triangleright$ &, & $\rightarrow$ & , &, & , & , \\
\hline
\end{tabular}




\section{CONCLUSOES}

Em face dos resultados obtidos e estribados na análise estatística, concluimos:

1) De acôrdo com a análise da variância - Test $F$ - a variabilidade dos processos de WIIEELER-STANSBY e do Acido sulfúrico, nos níveis de $5 \%$ e $1 \%$ pode ser, no caso da banha e do óleo de caroço de algodão, atribuivel ao acaso, o mesmo não se dando com referência à manteiga. No entretanto, devido ia alta percentagem dessa variabilidade, não são os mesimos recomendáveis.

2) Dos processos examinados, o mais scnsivel para determinação do Indice de Peróxidos em óleo de caroço de algodão, banha e manteiga, contrariamente do observado por STANsBY em óleo de peixe, é o do Ácido clorídrico, por apresentar menor percentagem de variabilidade.

3) O processo de WhEELER-STANSBY apresentou alta percentagem de variabilidade mesmo $\mathrm{cm}$ amostras de jêso bem próximo.

4) O processo do Áciclo sulfúrico apresentou, no óleo de caroço de algodão e na manteiga, as maiores percentagens de variabilidade, comparativamente aos outros dois.

\section{RESLMO}

Os autores determinaram o indice de Peróxidos no óleo de caroço de algodão, na banha c na manteiga, pelos processos de WHEELER (modificado poi STaNsBY), do Ácido clorídrico e do Ácido sulfúrico, tal como foram descritos por STANSBY. Executaram as determinações pelos três processos utilizando-se da mesma amostra e realizando-as em número de doze para cada uma delas.

Tos resultadns obtidos, a anós submetê-los à análise estatistica - Test $\mathrm{F}$ - concluem:

1) De acôrdo com a análise da variância - Test $F$ - a variabilidade dos processos de WHEFIAR-STANSBY e do Ácido sulfúrico, nos níveis de $5 \%$ e $1 \%$ pode ser, no caso da banha e do ólco de caroço de algodāo, atribuível ao acaso, o mesmo não se dando com referência à manteiga. No entretanto, devido a aita pereentagem dessa variabilidade, não são os mesmos recomendáveis.

2) Dos proeessos examinados, o mais sensivel para determinação do Indice de Peróxidos em óleo de caroço de algodão, banha e manteiga, contràriamente ao observado por STANSBY em óleo de peixe, é o do Acido cloridrico, por apresentar menor percentagem de variabilidade. 
3) O processo de WHEELER-STANSBY apresentou alta percentagem de variabilidade mesino $\mathrm{cm}$ amostras de pêso bem próximo.

4) O processo cio Ácido sulfúrico apresentou, no óleo de caroço de algodão e na manteiga, as maiores percentagens de variabilidade, comparativamente aos outros dois.

\section{CONCIJUSIONS}

In view of the results obtained, and bused upon statistical analysis, we draw the following conchusions:

1) Analysis of variance - Test F - was performed; according to it, variance of WHETLER-STANSBY's of sulphuric acid process, referring to lard and cotton-secd oil, may be due to chance. The same docs not go for butter. But, owing to the high percentage of this variance, they are not to be recommended.

2) The most accurate process for determining the rute of peruxide in cotton-seed oil, lard and butter, from those examined, is the one employing chlorhylric acid; it presents a lower rate of variance. STANBBY observed the opposite of this concerning fish oil.

3) WhEFLER-STANSBY's process presented high rate of varianes, even when samples were aproaimately of the same weight.

4) Sulphuric acid process presented higher rates of variability as compared with the other two, when concening butter and cottion-secd oil.

\section{SEMHARY}

The $A A$. determined the rates of peroxide in cotton-seed oil, lari and butten, by the processes of W WEELER (modificd by STANSBY), of chlorhydric acid and of sulphuric acid, the very way STANSBY described them. Determinations were made by all three processes, making use of the same sample, numbering twelve for each. The $A A$. were able to draw the following conclusions with the results obtained. after stbmitting them to statistical analysis - Test F:

1) Analysis of varime - Test $F$ - was performed; according to it, varunce of WHESLER-STANSBX's of sulphuric acid process, referring to lard amd cotton-seed oil, may be due to chance. The same does not go for butcr. But, owing to the high percentage of this variance, they wre not to be recommended.

3) The most accurate process for determining the rate of peroxide in colton-seed oil, lavd end bnter, from those cxamined, is the one enuloying chlorhydric acid; it presents a lower vate of variance. STANSiY observed the opposite of this concernig fish oil. 
3) WHEELER-STANSBY's process presented high rate of variance, even when samples were aproximately of the same weight.

4) Sulphuric acid process presented higher rates of variability as compared with the other two, when concerning butter and cotton-seed oil.

\section{BIBLIOGRAFIA}

STANSBY, M. - 1941 - Jetermination of peroxide values for rancidity in fish oils. Jour. Ind. Eng. Chem., Anal. ed. 13: 627.

WheEler, D. H. - 1932 - Peroxide formation as a measure of autoxidative deterioration. Oil \& Soap, 9: 89-97.

Winton, A. L. - Winton, K. B. - 1945 - The analysis of foods - New York, John Wiley \& Sons, Inc. 